\title{
The use of celery stalks powder of infrared drying in bakery products
}

\author{
Anastasiia V. Kopylova ${ }^{1,2}$, Oleg K. Motovilov ${ }^{2}$, Aleksandr N. Sapozhnikov ${ }^{1, *}$, Timofey A. \\ Levin $^{1}$, and Inna $Y$. Rybakolnikova ${ }^{1}$ \\ ${ }^{1}$ Novosibirsk State Technical University, Prospekt K. Marksa, 20, 630073 Novosibirsk, Russia \\ ${ }^{2}$ Siberian Research and Technological Institute of Agricultural Production Processing, Siberian \\ Federal Scientific Centre of Agro-BioTechnologies of the RAS, P.O. box 267, 630501 Krasnoobsk, \\ Novosibirsk region, Russia
}

\begin{abstract}
Celery stalks are a source of useful nutritional substances. However, their shelf-life is short, so processing them into the powder of infrared (IR) drying is the optimal way to keep their useful properties. Using celery stalks in powder form can prolongate their shelf-life and introduce them into bakery products formulations. Thus, bakery products range will expand, what contributes to the aims of bakery enterprises sustainable development. The paper shows the research results in the development of new bakery production using celery stalks powder of IRdrying. The experiments showed that the celery stalks powder slightly changes carrying out the technological process, and the bakery product has got high sensory characteristics and nutritional value. So, the developed technology can be implemented practically.
\end{abstract}

\section{Introduction}

Bakery industry is one of the leaders in Russian food industry. Bread and bakery products are essential food products for country population, so their production process is carried out continuously at bakery enterprises of different capacities and types of ownership. The industrialization of bread and bakery production took place after the formation of the USSR in the 1920s. From that time and until today, high industrial bread production is typical for Russian bakery industry. It is concentrated in large factories and bakeries, which inevitably have an impact on the environment. Therefore, it becomes urgent to revise the functioning of existing bakery industries to comply their functioning with the principles of sustainable development. According to bakery industry, these principles are saving and rational use of resources, and in particular, enrichment of bakery products with missing nutrients.

It is known that high-grade wheat flour, which is used in most bakery products as a main ingredient, is a refined product. The bran formed during wheat grain milling is not always used as a bakery products additive, since it can significantly reduce their sensory properties. Thereby, it is promising to enrich bakery products with food ingredients of plant origin, which have positive impact on both sensory properties and nutritional value of

\footnotetext{
*Corresponding author: a.sapozhnikov@corp.nstu.ru
} 
bakery products. In turn, enriched bakery products can get therapeutic and prophylactic properties [1].

Celery (Apium graveolens L.) is a promising plant raw material for enriching bakery products. It is known that in can be used not only as a food, but also in medicinal purposes, since it has high antioxidant and antimicrobial activity [2,3]. Different parts of celery can be eaten. The best-known part of celery is root, while leaves and stalks are used less. At the same time, stalks also contain vitamins and antioxidants [4], which allows to use them as a food ingredient with biologically active substances. However, celery stalks do not have long shelf-life, so they must be processed for its extending while keeping of most of their nutrients and antioxidant activity [5].

Shelf-life of fresh celery can be extended by using special polymer packaging [6]. Drying is also a rational option for extending celery shelf-life since it allows to store the dried product for a long time without additional energy costs. It is also advisable to keep dried celery stalks in powder form [7] because it allows to use them in technological process without any preparations. Besides, it is known that celery powder introduction into bakery products formulations within $1 . .2 \mathrm{~g}$ per $100 \mathrm{~g}$ of flour can improve their nutritional value and antioxidant activity [8].

There were previously carried out several studies in drying of different celery parts with hot air [9-11], microwave radiation [9], freeze- [11] and spray-drying [12], and combined methods. The obtained production had got high quality, but in general these methods are energy-consuming and have a complex hardware design. In this regard, promising methods for celery stalks drying is infrared (IR) drying method with further fine grinding. The main advantages for IR-drying of plant raw material are low drying temperatures $\left(40 \ldots 60{ }^{\circ} \mathrm{C}\right)$, simplicity and scalability of the process [13].

\section{Materials and methods}

The main raw materials for obtaining of bakery product samples were high-grade wheat flour and whole grain wheat flour of "The French Thing" trademark produced at "Kombinat Khleboprodutkov Starooskolskii" company (Belgorod region, city of Staryi Oskol, Russia), first-grade wheat flour of "Aleika" trademark produced at "Aleiskzernoprodukt" company (Altai region, city of Aleisk, Russia) and pressed yeast produced at "Novosibirsk Yeast Plant" company (Novosibirsk, Russia).

The other raw materials: hard cheese of Dutch sort, bacon (uncooked smoked brisket), celery stalks, sunflower oil and salt were purchased in the retail enterprises of Novosibirsk.

Obtaining and quality evaluation of bread samples were carried out at the Technology and Organization of Food Industries Department of Novosibirsk State Technical University NETI. There were prepared control bread sample with the use bacon of and cheese in its formulation (sample № 1) and experimental bread sample with the use of bacon, cheese, fresh celery stalks and celery stalks powder of IR-drying (sample № 2).

The main feature in bread samples preparing was the use of liquid sourdough - poolish based on high-grade wheat flour and yeast, as well as autolysis - semi-finished product based on wheat flour of the first grade, whole wheat flour and water. Both poolish and autolysis were kept at $24 \ldots 26^{\circ} \mathrm{C}$ for $1 \mathrm{~h}$ before dough kneading, and poolish was also kept at $4 \ldots 6^{\circ} \mathrm{C}$ more than $12 \mathrm{~h}$ for its ripening.

Two dough samples were kneaded in the bowl of Sigma TAURO 22-2 V dough kneader (Italy), and baked in Sveba Dahlen DC-12 electric hearth oven (Sweden). All other technological operations were carried out manually using special kitchen utensils. The dough pieces were formed in rattan forms.

The flowchart showing the preparing process of sample № 1 is presented in Fig. 1. 


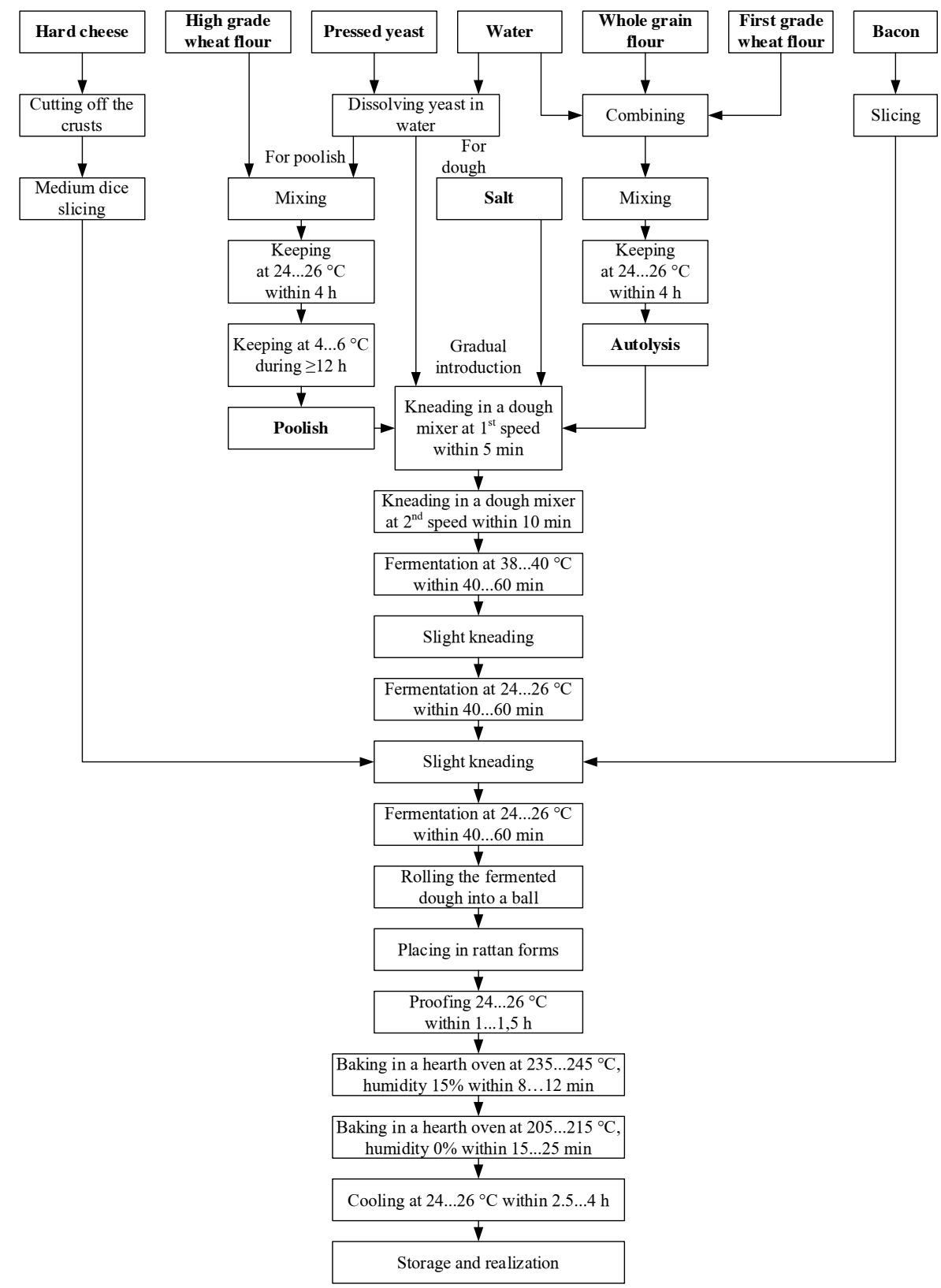

Fig. 1. Flowchart of bread sample preparing process

The difference between the preparation technology of sample № 1 and sample № 2 was in the introduction of IR-drying powder of celery stalks in an amount of $6 \%$ of the mass of all flour types used while dough kneading and in the introduction of diced cheese, bacon and celery stalks into the dough during its second kneading. Before introducing, diced celery stalks were fried on sunflower oil. The value of $6 \%$ for the introducing of celery stalks powder into the dough was established after preliminary experiments.

Drying of celery stalks was carried out at the experimental infrared dryer (Russian patent № 2265169). The IR-radiation generators were quartz halogen tubular lamps KGT220-1000, which worked in pulsed mode in ratio of switching on and off 1:3 accordingly. 
At $60{ }^{\circ} \mathrm{C}$ lamps switched off automatically. This upper temperature level was established as a result of preliminary experiment [13].

Sensory evaluation of baked bread samples was carried out after $2.5 \ldots 4 \mathrm{~h}$ from the end of baking process according to Russian national standard GOST 31986-2012 "Public catering service. Method of sensory evaluation of catering products" for the following characteristics:

- appearance;

- scent;

- taste;

- color;

- consistency.

Every sensory characteristic was evaluated on the 5-point scale (5 indicates the best and 1 implies the worst) by 7 semi-trained panelists ( 3 lecturers and 4 students). As a result of the evaluation, the average points for each characteristic were obtained.

Regarding the indicators of taste and scent as the main criteria of choosing bread and bakery products by the consumers, the descriptor-profile method was applied. This method allows to obtain an objective evaluation of individual properties for food production samples, which will allow to regulate them while changing and improving their formulations and production technology [14].

Every indicator value varied from 0 to 5 points, where 5 points is the highest grade of taste and scent, and 0 points meant the lack of appropriate characteristics for taste and scent.

Nutritional and energy values of bread samples were calculated and evaluated according to reference data from "Chemical Compositions of Russian Food Products Manual" (2002).

\section{Results and discussion}

Profilogram of control and experimental bread samples sensory evaluation is presented in Fig. 2.

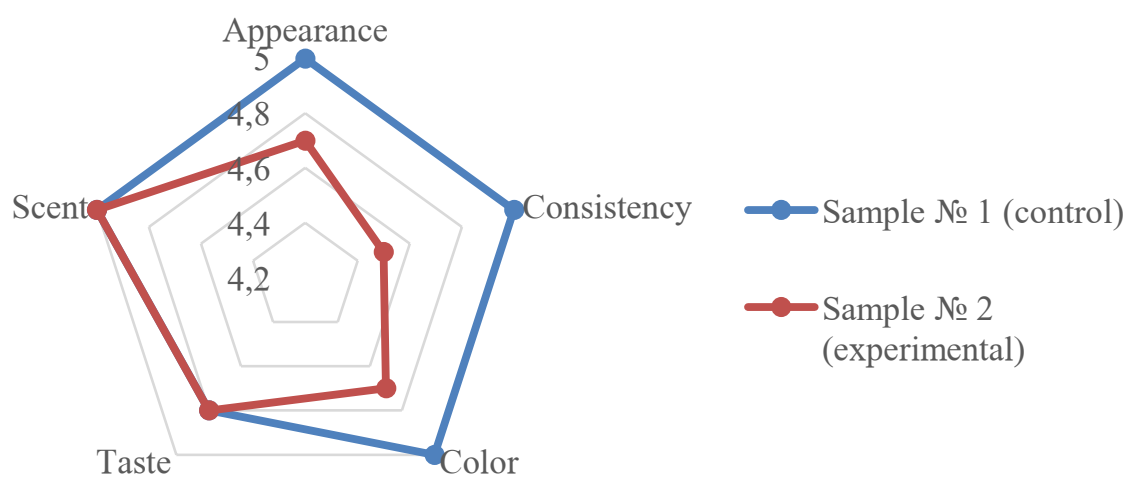

Fig. 2. Sensory evaluation of bread samples

Sample № 1 got the highest points (5.0) for all indicators except taste (4.8). The taste and scent of sample № 2 remained at the same level, appearance and color lowered to 4.7 points, and consistency lowered to 4.5 points. The reasons for lowering of these indicators were grayish crumb color because of introducing celery stalks powder of IR-drying into the dough. Crumb consistency in sample № 2 was moister than in sample № 2. It was also 
noted that dough rise of sample № 2 during fermentation was visually less than dough rise of sample № 1, and baked experimental sample was vaguer then control sample.

Lowering of appearance, consistency, color and scent points for sample № 2 can also be because it is untypical for Russian consumers. New signature bakery products, where fillings are introduced directly into the dough, are not widespread in Russia. For color and consistency improving, different amounts of celery stalks powder will be introduced in the dough and its optimal rate will be determined.

According to sensory evaluation, the sample № 2 acquired a sour taste (1.5 points), and extent spicy ( 0.8 points) and more bitter tinge (by 0.5 points). Sweet (1.3 points) and salty (3.8 points) tinges remained at the same level.

At the same time, the scent became more pleasant (by 0.7 points), but also remained at the same level concerning its specificity to incoming products (5.0 points). It also became slightly more specific (by 0.5 points) and intense (by 0.7 points). Changes in indicators are explained by introducing of fresh and IR-dried celery into the dough for sample № 2 . Therefore, undesirable changes in taste and scent can be corrected by adding various spices and seasonings in combination with used main and additional ingredients, as well as changing the ratio of the ingredients.

In the Table 1, calculation of bread samples nutritional value is shown.

Table 1. Calculation of bread samples nutritional value

\begin{tabular}{|l|c|c|c|c|c|}
\hline \multirow{2}{*}{ Nutrients } & \multirow{2}{*}{$\begin{array}{c}\text { Daily } \\
\text { norm }\end{array}$} & \multicolumn{2}{c|}{ Content in 100 g } & \multicolumn{2}{c|}{ Daily norm percentage, \% } \\
\cline { 3 - 6 } & 75 & sample № 1 & sample № 2 & sample № 1 & sample № 2 \\
\hline Proteins, g & 6.1 & 5.1 & 8.1 & 6.8 \\
\hline Lipids, g & 83 & 4.9 & 5.2 & 5.9 & 6.3 \\
\hline Carbohydrates, g & 211 & 28.6 & 23.1 & 13.6 & 10.9 \\
\hline Energy value, kcal & 2500 & 183 & 159 & 7.3 & 6.4 \\
\hline \multicolumn{5}{|c|}{ Minerals } \\
\hline $\mathrm{Na}, \mathrm{mg}$ & 2400 & 483.3 & 445.2 & 20.1 & 18.6 \\
\hline $\mathrm{K}, \mathrm{mg}$ & 3500 & 102.7 & 220.8 & 2.9 & 6.3 \\
\hline $\mathrm{Ca}, \mathrm{mg}$ & 1000 & 92.1 & 95.9 & 9.2 & 9.6 \\
\hline $\mathrm{Mg}, \mathrm{mg}$ & 400 & 25.7 & 36.5 & 6.4 & 9.1 \\
\hline $\mathrm{P}, \mathrm{mg}$ & 1000 & 111.4 & 112.7 & 11.1 & 11.3 \\
\hline $\mathrm{Fe}, \mathrm{mg}$ & 14 & 1.2 & 1.3 & 8.6 & 9.3 \\
\hline \multicolumn{7}{|c|}{ Vitamins } \\
\hline $\mathrm{B} 1, \mathrm{mg}$ & 1.5 & 0.02 & 0.02 & 1.6 & 1.5 \\
\hline $\mathrm{B} 2, \mathrm{mg}$ & 1.8 & 0.04 & 0.18 & 2.2 & 10.0 \\
\hline $\mathrm{PP}, \mathrm{mg}$ & 20 & 0.3 & 0.3 & 1.7 & 1.7 \\
\hline
\end{tabular}

The combination of ingredients introduced into sample № 2 increased its content of lipids in $100 \mathrm{~g}$ by $0.3 \mathrm{~g}$, potassium - by $118.1 \mathrm{mg}$, calcium - by $3.8 \mathrm{mg}$, magnesium - by $10.8 \mathrm{mg}$, phosphorus- by $1.3 \mathrm{mg}$, vitamin $\mathrm{B}_{2}-$ by $0.83 \mathrm{mg}$. Thereby, their daily norm percentage increased, and thus enrichment of sample № 2 also increased. At the same time, in sample № 2 protein content lowered by $1 \mathrm{mg}$, carbohydrates - by $5.5 \mathrm{mg}$, sodium - by $38.1 \mathrm{mg}$, which also lowered its energy value by $24 \mathrm{kcal}$. Vitamins $\mathrm{B}_{1}, \mathrm{~B}_{2}$ and PP amounts remained at the same level. In the future, optimization of nutritional and energy value of developed bakery product can be achieved by mathematical modelling of its formulation.

\section{Conclusions}

1. Study on formulation and technology development of bread with the use of celery stalks in fresh and powdered forms, cheese and bacon showed high indicators of 
developed product sample, and the feasibility of its further improving concerning its sensory characteristics and nutritional value.

2. In the future, it is recommended to study different methods of introducing celery stalks and leaves into the dough, to work out various amounts of IR-dried celery stalk powder and check its effect on specific volume and porosity of bread samples.

3. The calculated nutritional value of experimental sample showed its higher points in comparison with control sample. The obtained product is more enriched with useful nutritional substances and has lesser energy value. At the same time, for confirming calculated nutritional and energy value of obtained bread, it is recommended to analyze the chemical composition of bakery products samples practically.

4. The implementation of new types of bread and bakery production will expand their range and will contribute to sustainable development of bakery enterprises.

\section{References}

1. S. U. Sergieva, T. V. Bagaeva, L. Z. Gabdukaeva, O. A. Reshetnik, EurAsia. J. of BioSci., 13, 1297 (2019)

2. M. S. Al Aboody, Bioinformation, 1, 147 (2021)

3. W. Kooti, N. Daraei, Evid.-base. Compl. Alternative. Med., 4, 1029 (2017)

4. V. A. Kharchenko, A. I. Moldovan, N. A. Golubkina, A. A. Koshevarov, G. Caruso, Vegetable crops of Russia, 2, 82 (2020)

5. M. P. Gilingerne, C. Orban, E. C. Csajbokne, Acta Horticulturae, 1209, 155 (2018)

6. V. Rizzo, G. Muratore, J. Food Eng., 90, 124 (2009)

7. I. Staniszewska, L. Dzadz, K. W. Nowak, M. Zielinska, LWT, 146, 111440 (2021)

8. N. F. Wang, Y. Xu, H. M. Chao, M. Zhang, Y. B. Zhou, M. C. Wang, J. Food Sci. Technol., 57, 1710 (2020)

9. Y. Chen, C. Song, Z. Li, H. Chen, G. Jin, J. Food Process. Preserv., 1, e14310 (2019)

10. M. P. Nguen, Res. Crop., 2, 396 (2020)

11. A. Özkan Karabacak, S. Suna, C. E. Tamer, Ö. U. Çopur, Qual. Assur. Saf. Crop., 2, 193 (2018)

12. M. K. Movahhed, M. Mohebbi, J. Food Process. Preserv., 2, 212 (2016)

13. A. N. Sapozhnikov, S. D. Sleptsov, M. A. Grishin, A. V. Kopylova, T. A. Levin, J. Phys. Conf. Ser., 1677, 012177 (2020)

14. V. A. Matison, N. I. Arutyunova, E. D. Goryacheva, Pishchevaya promyshlennost', 6, $52(2015)$ 